balance for water. The results in six patients were compared with those obtained during intragastric feeding of the same patients. The intragastric diet of milk powder and glucose maintained metabolic balance except for a negative chloride balance. The urinary total nitrogen, ammonia, and aminoacids were similar on the two diets, but urea excretion was reduced on the intravenous diet, suggesting a decrease in protein catabolism.

The investigation was suggested by Professor A. Wilson and Dr. E. Sherwood Jones and supported by grants from the Liverpool
United Hospitals Research Committee, Regional Hospital Board, and the Cancer and Polio Research Club of Liverpool.

\section{REFERENCES}

Folin, O. (1905). Amer. F. Physiol., 13, 117.

Jones, E. S., and Peaston, M. J. T. (1966), Practitioner. In press.

Jones, E. S., and Peaston, M. J. T. (1966). 19.

Moore, F. D. (1959). Metabolic Care of the Surgical Patient, p. 467. Saunders, Philadelphia.

Peters, J. P., and Van Slyke, D. D. (1931). Quantitative Clinical Chemistry, vol. 1 , p. 339 . Baillière, Tindall and Cox, London

Wadström, L. B., and Wiklund, P. E. (1964). Acta chir. scand., Suppl. No. 325 , p. 50 .

Wretlind, A. (1964). Ibid., Suppl. No. 325, p. 31.

\title{
Four Cases of Bromism
}

\author{
G. NUKI,* M.B., M.R.C.P. ; P. RICHARDSON, $\dagger$ M.B., B.S. ; M. J. GOGGIN, $\ddagger$ M.B., B.S. \\ R. I. S. BAYLISS, $\S$ M.D., F.R.C.P.
}

Brit. med. F., 1966, 2, 390-391

Although bromide poisoning was described by Huette (1850), it was Wuth (1927) who drew attention to its high incidence in psychiatric hospital wards. The "bromide hazard" was well recognized in the 1930s (Diethelm, 1930 ; Wagner and Bunbury, 1930 ; Barbour et al., 1936), when vast quantities of bromides were prescribed. Today, however, when their use has been largely replaced by barbiturates, phenothiazines, and other tranquillizers, it seems likely that bromide intoxication is not considered promptly enough in the differential diagnosis of obscure neuropsychiatric problems.

\section{Case 1}

A 59-year-old woman had been in poor health for many years. Her main complaints were of constipation and fatigue, which were so extreme that she seldom went out and spent much of her day resting on a sofa. At times she was confused, her speech slurred, and her memory poor. In June 1965 she slipped and fractured the neck of her femur. Her post-operative condition gave cause for alarm. She was drowsy, disorientated, and incontinent. She was emaciated; her tongue was dry and furred. She had bilateral ptosis, constricted pupils, extreme muscular weakness, and depressed tendon reflexes. There were no localizing signs in the central nervous system, and biochemical tests showed no evidence of renal, hepatic, or other metabolic disorder. It was then learned that she had for many years been taking an "innocuous sleeping mixture" prescribed originally for her husband in 1939. Each night she took at least three tablespoonfuls, containing in all 30 minims $(1.5 \mathrm{ml}$.) of tincture of morphine and $60 \mathrm{gr}$. (3.9 g.) of ammonium bromide. The serum bromide level was found to be $380 \mathrm{mg}$./ $100 \mathrm{ml}$. Her mental and physical condition improved gradually but strikingly on withdrawal of the bromide mixture and the administration of ammonium chloride and mersalyl.

\section{Case 2}

A 76-year-old woman, admitted to hospital for terminal nursing in December 1964, had been taking mist, gelsem. et hyoscy. co. B.N.F. for trigeminal neuralgia since 1952. In 1958 she began to have lapses of memory. A year later a diagnosis of cerebral arteriopathy was made when she began to have paranoid delusions. Her condition gradually deteriorated, and by 1961 she was incapable

- Medical Registrar, Westminster Hospital, London.

† Senior House Officer in Medicine, St. Stephen's Hospital, London.

t Medical Registrar, Mount Vernon Hospital London.

Consultant Physician, Westminster Hospital, London. of doing housework and had made several suicidal gestures. During the month before admission she became incoherent and developed incontinence of urine, while continuing to complain of trigeminal neuralgia. Examination revealed a cachectic, dehydrated old woman who moaned and muttered unintelligibly but showed no localizing signs in the central nervous system. Simple rehydration produced such striking clinical improvement that a review of her drug therapy was suggested. As mist. gelsem. et hyoscy. co. B.N.F. contains $650 \mathrm{mg}$. of bromide per $15 \mathrm{ml}$. the serum bromide level was determined and found to be $285 \mathrm{mg} . / 100 \mathrm{ml}$. She was treated with sodium chloride, a high fluid intake, and mercurial diuretics. Clinical improvement roughly paralleled the fall in her serum bromide, though she had some episodes of confusion. Three months after admission she was well, apart from slight lapses of memory, and her serum bromide had fallen near to zero.

\section{Case 3}

A 59-year-old man was admitted to hospital in May 1965 with a six-months history of progressive mental deterioration and a twomonths history of dragging his right foot. A week before admission he became paranoid and violent before lapsing into a semicoma. He was found at home, in bed, dehydrated, too weak to move, and surrounded by broken furniture. He was dysarthric and his pupils were constricted. Tendon reflexes were diminished in both legs but increased in the right arm, with an equivocal right plantar response.

On admission to a general hospital medical ward, examination revealed sordes in the mouth and an acneiform rash on the chest. There was nominal dysphasia as well as dysarthria and disorientation. He had mild incoordination of the left arm and leg, but there were no pyramidal signs. Investigation showed normal serum electrolytes, urea, sugar, vitamin $\mathrm{B}_{12}$, Wassermann reaction, Kahn test, and chest and skull radiographs. Lumbar puncture showed nothing abnormal except for a cerebrospinal fluid protein of $110 \mathrm{mg} . / 100 \mathrm{ml}$.

The patient was transferred to a neurosurgical unit, where ultrasound suggested a shift from left to right, though a left carotid arteriogram and ventriculography were normal. An E.E.G. was not contributory, as it was performed after burr-holes had been made.

A space-occupying lesion having been excluded, he was returned to the medical ward, where over a period of days he improved to the extent of being able to hold a rational conversation. It then transpired that he had taken a bromide-and-chloral mixture for 18 years since his discharge from a mental hospital after what was described as an hysterical illness. In the week before admission he had doubled his dose, as it seemed to be losing its effectiveness in calming his symptoms of anxiety. His serum bromide level 10 days after the last dose was still $202 \mathrm{mg} . / 100 \mathrm{ml}$. He was treated 
with sodium chloride, copious fluids, and mercurial diuretics, and later with frusemide. Apart from transient paranoid delusions, gradual clinical improvement accompanied a steady fall in the serum bromide. This fell to almost zero when he left hospital, three months after admission.

\section{Case 4}

A 51-year-old woman had been unwell since the birth of her son, now aged 25 . She complained of excessive tiredness, a poor memory, insomnia, irritability, tearfulness, and failure to gain weight. Extensive investigations had failed to reveal any organic disease, and treatment with antidepressants had brought no improvement. Although when first seen she denied taking any medicines or tablets, she later admitted that ever since her son was born she had been taking thrice daily a "nerve tonic," which she had forgotten to mention because it was so much part of her daily routine. The "tonic" was mist. pot. brom., and the serum bromide level was $186 \mathrm{mg} . / 100 \mathrm{ml}$. It remains uncertain how much of her symptomatology is due to bromism and how much to psychogenic factors, as she has not attended again, and it is thought that she is still taking the mixture.

\section{Comment}

These cases illustrate many of the féatures of severe bromide intoxication described in the literature.

Although there is no characteristic clinical pattern, common symptoms are tiredness, weakness, and inability to concentrate. Gradual mental deterioration, with episodic delusions and hallucinations, may occur. Drowsiness progressing to stupor and coma, with varying levels of consciousness and bizarre fluctuating neurological signs, has been described; the most common of these signs being dysarthria, tremor, ataxia, pupil abnormalities, and tendon reflex changes (Perkins, 1950).

Halitosis and sordes are often present, and may be due to dehydration alone or to the secretion of hydrogen bromide in the stomach (Goodman and Gilman, 1955).

A bromide rash may be helpful in diagnosis, but it occurs in only a small percentage of cases. An elevated protein content in the cerebrospinal fluid is well documented in bromide poisoning (Claiborne, 1935 ; Greenblatt et al., 1945 ; Perkins, 1950). E.E.G. changes have been recorded (Greenblatt et al., 1945).

Although bromide intoxication may present as a specific psychiatric syndrome (Curran, 1944), the clinical picture can be so variable that diagnosis must depend on remaining aware of its possible presence. Suspicion can be confirmed by a simple urine-screening test (Reye and Joffe, 1959) and followed if necessary by estimation of the serum bromide level (Barbour et al., 1936). Levels over $150 \mathrm{mg} . / 100 \mathrm{ml}$. (19 mEq/1.) are definitely toxic, while those between 75 and $150 \mathrm{mg} . / 100 \mathrm{ml}$. are highly suggestive of bromide intoxication.

Since experimental work has shown that the kidney preferentially retains bromide at the expense of chloride (Bodansky and Modell, 1941), treatment is based on administering sodium chloride with fluids and forcing a diuresis. Mercurial diuretics (Hussar and Holley, 1956), mannitol infusions, or, in extreme cases, haemodialysis (Wieth and Funder, 1963) have been used. Theoretically the new highly chloruretic agents, ethacrynic acid and frusemide, might be more effective than mercurial diuretics in promoting the excretion of bromide, but this was not demonstrable in Case 3.

Despite occasional warnings (Emery and Richards, 1963 ; Segal, 1964) it may not be generally realized that more than two dozen compounds containing bromide are available today (see Table). The bromide content is not immediately evident in many of them and many are available without prescription. This seems particularly dangerous, as patients habituated to taking bromide are prone to increase their consumption to try to alleviate symptoms which are actually the result of toxicity. In two of the cases described, however, a physician was responsible for prescribing the drug.
Although there is evidence that the incidence of bromism has decreased in the past 30 years (Ewing and Grant, 1965), four such severe cases seen during 1965 suggest that it remains a hazard to be borne in mind in obscure neuropsychiatric disorders, especially in the geriatric age group.

\section{Currently Available Compounds Containing Bromide}

Preparations Obtainable Without Prescription

Bodryl (Parke Davis)

Bromocarpine (Inter-Alia Pharm.)

Bromoform elixir

Bromo-Seltzer (Thos. Marns Ltd., Hounslow)

Broval (Gedeon Richter Ltd., London)

Calcibronat (Sandoz Products)

Coneuro (Hewlett)

Fennings' cough mixture (J. Sanger and Sons, Lancing)

Gower's mixture (various formulae)

Mixture of potassium bromide (B.P.C.)

Mixture of potassium bromide and nux vomica (B.P.C.)

Mixture of potassium bromide and valerian (B.P.C.)

Dr. Niblett's nerve sedative (C. P. Niblett, London)

Otosedan (Coates and Cooper)

Robuval (Inter-Alia Pharm.)

Preparations Obtainable on Prescription Only

S4 Bromevan (Evans Medical Supplies)

S4 Bromidia (Inter-Alia Pharm.)

DD Bromodeine (Crookes)

S4 Carbromal (B.P.C.)

S4 Gabail (Anglo-French)

S1 Gelineau dragées (Wilcox, Jozeau ; Mousnier-Delerme, Antony

S1 Gelineau dra

S4 Mist. somni opiate (Three-Fifteens)

DD Mulsivin (Rybar)

S1 Schedule 1: poisons. S4 Schedule 4: poisons. DD Dangerous drugs.

Preparations No Longer in B.P.C. which are still Occasionally Prescribed Mixture of potassium bromide and chloral (B.P.C.)

Mixture of chloral and potassium bromide for infants (B.P.C.)

Mixture of gelsemium and hyoscyamus co. (B.P.C.)

\section{Summary}

Four cases of severe bromide poisoning seen in 1965 are presented. The clinical features, diagnosis, and treatment of bromism are briefly reviewed.

Twenty-six compounds, currently available, are listed; fifteen of these can be purchased without prescription. The peculiar hazard to the patient of increasing intake in order to try to alleviate symptoms which actually arise from bromide toxicity is stressed.

It is suggested that the variability of the clinical picture, together with failure to consider bromide intoxication early enough, may result in delay in diagnosis. A plea for remaining alert to the possibility of bromism in obscure neuropsychiatric problems, especially in the elderly, is made.

We wish to thank Dr. V. Edmunds and Dr. F. Dudley Hart for permission to include patients under their care.

\section{REFERENCES}

Barbour, R. F., Pilkington, F., and Sargant, W. (1936). Brit. med. F., 2, 957.

Bodansky, O., and Modell, W. (1941). F. Pharmacol. exp. Ther., 73, 51. Claiborne, T. S. (1935). New Engl. $\dot{F}$. Med., 212, 1214.

Curran, F. J. (1944). f. nerv. ment. Dis., 100, 142.

Diethelm, O. (1930). Ibid., 71, 151, 278 .

Diethelm, O. (1930) Ibid., 71, 151, 278. and Richards, A. G. (1963). Canad. med. Ass. 7., 89, 354.

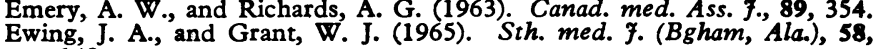
148.

Goodman, L. S., and Gilman, A: (1955). Pharmacological Basis of Therapeutics, 2nd ed. Macmillan, New York.

Greenblatt, M., Levin, S., and Schegloff, B. (1945). Arch. Neurol, Psychiat. (Chic.), 53, 431 .

Huette, C. (1850). Mém. Soc. Biol., $2,19$.

Hussar, A. E., and Holley, H. L. (1956). Amer. F. Med., 20, 100.

Perkins, H. A. (1950). Arch. intern. Med., 85, 783.

Reye, G. H., and Joffe, J. R. (1959). Amer. F. Psychiat., 116, 166.

Segal, M. (1964). Brit. med. f., 2, 942.

Wagner, C. P., and Bunbury, D. E. (1930). F. Amer. med. Ass., $9 \mathcal{H}_{1}$ 1725 .

Wieth, J. O., and Funder, J. (1963). Lancet, 2, 327

Wuth, O. (1927). Ұ. Amer. med. Ass., 88, 2013. 